\title{
Effect of penehyclidine hydrochloride on heart rate variability in hysteroscopy
}

\author{
XIAO-BO LIU*, SHU PAN* ${ }^{*}$ XI-GE YANG, ZHI-WEN LI, QING-SHAN SUN, \\ ZHUANG ZHAO, HAI-CHUN MA and CHENG-RI CUI \\ Department of Anesthesiology, First Hospital of Jilin University, Changchun, Jilin 130021, P.R. China
}

Received May 4, 2014; Accepted December 23, 2014

DOI: $10.3892 /$ etm.2015.2497

\begin{abstract}
In order to evaluate the effect of different doses of penehyclidine hydrochloride (penehyclidine) on heart rate (HR) and HR variability (HRV) in hysteroscopy, 180 patients (American Society of Anesthesiologists grade I-II) were randomized equally to three groups: $0.5 \mathrm{mg}$ penehyclidine and intravenous anesthesia (group I), $1.0 \mathrm{mg}$ penehyclidine and intravenous anesthesia (group II) and saddle anesthesia combined with intravenous anesthesia (control group). HR and HRV, including total power (TP), low-frequency power (LF), high-frequency power (HF) and the LF to $\mathrm{HF}$ ratio $(\mathrm{LF} / \mathrm{HF})$, were recorded prior and subsequent to the induction of anesthesia ( $\mathrm{T}_{0}$ and $\mathrm{T}_{1}$, respectively), following the start of surgery $\left(\mathrm{T}_{2}\right)$ and following completion of surgery $\left(\mathrm{T}_{3}\right)$. HR was lower at $\mathrm{T}_{2}$ than at $\mathrm{T}_{0}$ in the control patients, but no differences were observed in groups I and II. The HR at $\mathrm{T}_{2}$ was increased in group II compared with that in group I. TP in group II was significantly higher compared with that in group $\mathrm{I}$ at $\mathrm{T}_{2}$. At $\mathrm{T}_{1}$ and at $\mathrm{T}_{2}$, the LF and HF values were lower in group $\mathrm{I}$ than those in the controls. Patients in group II also had higher LF and $\mathrm{HF}$ at $\mathrm{T}_{2}$ than patients in group $\mathrm{I}$. The HF was higher at $\mathrm{T}_{2}$ than that at $\mathrm{T}_{0}$ in the controls; however, the HF and LF did not change significantly within groups I and II. No significant differences were observed in the LF/HF ratio among the three groups. At a dose of $0.5 \mathrm{mg}$, penehyclidine stabilized HRV and did not alter the autonomic nervous modulation of HR. A penehyclidine dose of $1.0 \mathrm{mg}$ may be superior to a dose of $0.5 \mathrm{mg}$ in maintaining HR, but is less effective at balancing sympathetic and parasympathetic activity.
\end{abstract}

Correspondence to: Dr Xi-Ge Yang, Department of Anesthesiology, First Hospital of Jilin University, 1 Xinmin Road, Changchun, Jilin 130021, P.R. China

E-mail: xige_yang@163.com

*Contributed equally

Key words: penehyclidine, heart rate, heart rate variability, hysteroscopy

\section{Introduction}

It is well accepted that the pre-operative administration of anticholinergic drugs can prevent adverse consequences of autonomic nervous system imbalance during surgery. Penehyclidine hydrochloride (penehyclidine) is a long-acting cholinergic receptor blocker manufactured in China (1). The main anesthetic mechanism of penehyclidine is selective blocking of central and peripheral M1 and M3 muscarinic acetylcholine receptors and N1 and N2 nicotinic acetylcholine receptors, without obvious effect on the M2 receptors distributed in the heart or presynaptic nerve membranes (1-3). The inhibition of M1 and M3 receptors leads to the direct inhibition of parasympathetic nerve effects and reflexive regulation of sympathetic nerves, thus stabilizing autonomic nerves and resulting in a central sedative effect (4). N1 receptors are responsible for modulating the release of neurotransmitters from neurons (5). The activation of N2 receptors results in muscle depolarization, the induction of action potentials and muscle contraction (5); therefore, blockade of N1 and $\mathrm{N} 2$ receptors leads to the inhibition of the overexcitation of autonomic nerves, and muscle relaxation. The activation of M2 receptors could modulate heart rate (HR) by affecting the conduction of electrical impulses through the atrioventricular node (6). Penehyclidine has been demonstrated to exert little or no effect on $\mathrm{M} 2$ receptors $(2,7,8)$ in rats and humans, and thus has little influence on HR.

Spectral analysis of the electrocardiogram is a non-invasive approach to monitor the sympathetic and parasympathetic outflow in various clinical situations (9). It has been demonstrated that HR variability (HRV), the slight fluctuation of the R-R interval between consecutive heartbeats, can be used to assess the autonomic control of the heart (10). HRV has great potential to detect cardiac sympathetic and vagus nervous system fluctuations (11), as well as to evaluate the influence of anticholinergic drugs (12). Among the HRV indices, total power (TP) represents the total power of the autonomic nervous activities; low-frequency power (LF), the frequency range from 0.04 to $0.15 \mathrm{~Hz}$, demonstrates the sympathetic alteration of HR and, to a lesser extent, indicates parasympathetic activity; high-frequency power (HF), the frequency range from 0.15 to $0.45 \mathrm{~Hz}$, is a measure of vagal nerve activity $(13,14)$. The $\mathrm{LF} / \mathrm{HF}$ ratio indicates the balance of sympathetic and parasympathetic activities $(10,13,14)$. An 
elevated $\mathrm{LF} / \mathrm{HF}$ ratio reflects enhanced sympathetic activity, while a low ratio indicates parasympathetic nerve activity.

The objective of the present study was to explore the effect of different doses of penehyclidine on sympathovagal balance, as determined by HRV, in patients undergoing gynecological hysteroscopic surgery.

\section{Materials and methods}

General information. Following approval from the Ethics Committee of Jilin University (Changchun, China; clinical trial registration no. H20020606), 180 patients undergoing gynecological hysteroscopic surgery [American Society of Anesthesiologists (ASA) grade I-II] were enrolled in this prospective study conducted between January and September 2012 at the First Hospital of Jilin University (Changchun, China). Informed consent was obtained from each patient. Patients with elevated body temperature, contraindication to saddle anesthesia, allergy to cholinergic drugs, history of glaucoma, liver or kidney dysfunction, an estimated blood loss of $>600 \mathrm{ml}$ during surgery and patients who were undergoing treatment with other anticholinergic drugs were excluded from this study.

Anesthesia methods. Subsequent to obtaining venous access, the patients were administrated sodium chloride solution prior to anesthesia. The patients were randomly divided into three groups ( $\mathrm{n}=60 /$ group): Penehyclidine $0.5 \mathrm{mg}$ (group I), penehyclidine $1.0 \mathrm{mg}$ (group II) or saddle anesthesia (control). Randomization was performed using sealed envelopes containing computer-generated random numbers. Penehyclidine (Force Fest Pharmaceutical Co., Chengdu, China) was administered intravenously $10 \mathrm{~min}$ before the induction of anesthesia. The control patients were given $0.8 \mathrm{ml} \mathrm{0.5 \%}$ bupivacaine (Wellhope Pharmaceutical Co., Ltd., Shanghai, China) intrathecally. All patients were administered midazolam (2 mg; Jiangsu Enhua Pharmaceutical Co., Ltd., Xuzhou, China) and fentanyl (1 $\mu \mathrm{g} / \mathrm{kg}$; Yichang Humanwell Pharmaceutical Co., Ltd., Yichang, China) prior to the start of surgery. Propofol (4-6 mg/kg/h; Libang Pharmaceutical Co., Ltd., Xi'an, China) was injected continuously during surgery. A single dose of fentanyl $(0.05 \mathrm{mg})$ was used when necessary. The ambient temperature was maintained at $20-25^{\circ} \mathrm{C}$.

HRV analysis. HRV was measured and recorded prior to the initiation of anesthesia $\left(\mathrm{T}_{0}\right)$, following the induction of anesthesia $\left(\mathrm{T}_{1}\right)$, at the start of surgery $\left(\mathrm{T}_{2}\right)$ and following the completion of the surgery $\left(\mathrm{T}_{3}\right)$. HR was monitored continuously using a multifunctional compact patient monitor (M8004A; Philips Medizin Systeme Böblingen GmbH, Böblingen, Germany). An HXD-I multi-function monitor (Huaxiang Co., Harbin, China) was used to monitor other parameters of HRV. Spectral analysis of HRV was performed following the manufacturer's instructions. HRV was assessed in classic frequency bands, including TP, LF (0.04-0.15 Hz), HF (0.15-0.45 Hz) and the ratio of $\mathrm{LF}$ to $\mathrm{HF}(\mathrm{LF} / \mathrm{HF})$.

Statistical analysis. All data are expressed as the mean \pm standard error of the mean for parametric variables with confirmed normality. Data were analyzed using SPSS statistical software version 13.0 (SPSS Inc., Chicago, IL, USA) and Prism 4.0 (GraphPad Software, Inc., San Diego, CA, USA). One-way analysis of variance (ANOVA) and the Mann-Whitney U and Fisher's exact tests, as appropriate, were used to compare general patient information. Two-way ANOVA with repeated measures (inter-group comparisons) and one-way ANOVA (intra-group comparisons) were used to determine the significance of differences in HR and HRV. Post hoc analysis was performed using the Bonferroni and Turkey tests. $\mathrm{P}<0.05$ was considered to indicate a statistically significant difference.

\section{Results}

Baseline characteristics. Patient baseline characteristics are shown in Table I. Sixty patients were enrolled in each group. No significant inter-group differences were observed in age, weight, height, ASA classification or baseline HR, oxygen saturation or systolic and diastolic blood pressure $(\mathrm{P}>0.05)$. Table II summarizes the HR and HRV data in the three study groups at different times. No statistically significant differences were observed among the three groups in the baseline $\left(\mathrm{T}_{0}\right) \mathrm{HR}$ and HRV variables, including TP, LF, HF and LF/HF.

Study data. Changes in HR observed in the study groups are shown in Fig. 1. No notable changes in HR were observed during surgery in either groups I or II; however, the HR was significantly lower at $\mathrm{T}_{2}$ than that at $\mathrm{T}_{0}$ in the control group $(70.30 \pm 1.74$ vs. $80.75 \pm 2.38, \mathrm{P}<0.01)$, and the HR at $\mathrm{T}_{2}$ was significantly higher in group II than that in group I $(77.15 \pm 2.43$ vs. $67.85 \pm 2.32, \mathrm{P}<0.05)$. No significant differences in HR were observed in groups I or II compared with the control group. No statistically significant differences in TP were observed between either group I or II and the control group (Fig. 2); however, the TP was elevated in group II compared with that in group $\mathrm{I}$ at $\mathrm{T}_{2}(9,895.51 \pm 5,385.66 \mathrm{vs}$. $3,001.14 \pm 586.05, \mathrm{P}<0.01)$. The $\mathrm{LF}$ and $\mathrm{HF}$ values in group I were significantly lower compared with those in the control group at $\mathrm{T}_{1}(\mathrm{LF}, 624.84 \pm 153.66$ vs. $1,996.14 \pm 329.25, \mathrm{P}<0.01$; HF, $587.59 \pm 153.26$ vs. $1,984.14 \pm 297.27, \mathrm{P}<0.05)$ and $\mathrm{T}_{2}(\mathrm{LF}$, $711.47 \pm 135.92$ vs. $1,813.89 \pm 296.82, \mathrm{P}<0.05 ; \mathrm{HF}, 994.81 \pm 262.35$ vs. $2,977.37 \pm 523.46, \mathrm{P}<0.001)$. Furthermore, the patients in group II had higher LF and $\mathrm{HF}$ values at $\mathrm{T}_{2}$ than the patients in group I (LF, $2,118.955 \pm 492.60$ vs. $711.47 \pm 135.92, \mathrm{P}<0.01$; HF, 2,738.22 \pm 585.43 vs. $994.81 \pm 262.35, \mathrm{P}<0.05)$. The HF value was higher at $\mathrm{T}_{2}$ than that at $\mathrm{T}_{0}$ in the control group $(2,977.37 \pm 523.46$ vs. $885.87 \pm 198.48, \mathrm{P}<0.01)$. The $\mathrm{HF}$ and LF values did not change significantly within groups I and II during the study.

No significant differences in the $\mathrm{LF} / \mathrm{HF}$ ratio were observed among the three groups (Fig. 3); the ratio remained constant throughout the study. Despite the fact that no significant differences were found in the control group at different times, the LF/HF gradually decreased between $\mathrm{T}_{0}$ and $\mathrm{T}_{2}$, and then increased to the starting level. $\mathrm{LF} / \mathrm{HF}$ was more stable, with little fluctuation, in groups I and II.

\section{Discussion}

The present study demonstrated that the pre-operative administration of penehyclidine resulted in a more stable HR 
Table I. Demographic and baseline characteristics of the three study groups.

\begin{tabular}{lccc}
\hline & Group I & Group II & Group III \\
\hline Age (years) & $48.45 \pm 2.96$ & $41.95 \pm 1.65$ & $39.25 \pm 2.76$ \\
Weight (kg) & $57.85 \pm 1.74$ & $58.50 \pm 1.38$ & $60.50 \pm 1.90$ \\
Height (cm) & $158.79 \pm 0.84$ & $158.65 \pm 0.89$ & $161.15 \pm 0.92$ \\
Baseline HR (bpm) & $74.56 \pm 3.07$ & $75.95 \pm 2.49$ & $80.75 \pm 2.38$ \\
Baseline SpO $(\%)$ & $98.55 \pm 0.32$ & $99.25 \pm 0.85$ & $99.10 \pm 0.19$ \\
Baseline SBP (mmHg) & $137.50 \pm 3.68$ & $139.25 \pm 3.88$ & $126.30 \pm 7.53$ \\
Baseline DBP (mmHg) & $96.25 \pm 16.42$ & $77.40 \pm 2.09$ & $80.0 \pm 2.11$ \\
ASA status (n/\%) & & & 0.251 \\
I & $22 / 36.6$ & $27 / 45.0$ & 0.179 \\
II & $38 / 63.3$ & $33 / 55.0$ & 0.379 \\
\hline
\end{tabular}

$n=60 /$ group. Results are presented as the mean \pm standard error of the mean, with the exception of ASA classification, where data are presented as the number/percentage. HR, heart rate; SpO2, oxygen saturation; SBP, systolic blood pressure; DBP, diastolic blood pressure; ASA, American Society of Anesthesiologists; $\mathrm{T}_{0}$, prior to the initiation of anesthesia; $\mathrm{T}_{1}$, following the induction of anesthesia; $\mathrm{T}_{2}$, at the commencement of surgery; $\mathrm{T}_{3}$, following the completion of surgery.

Table II. HR and HRV analysis of the three groups at different time-points.

\begin{tabular}{|c|c|c|c|c|c|}
\hline Parameter & Group & $\mathrm{T}_{0}$ & $\mathrm{~T}_{1}$ & $\mathrm{~T}_{2}$ & $\mathrm{~T}_{3}$ \\
\hline \multirow[t]{3}{*}{ HR (bpm) } & Group I & $74.65 \pm 3.07$ & $69.00 \pm 2.51$ & $67.85 \pm 2.32$ & $71.30 \pm 2.99$ \\
\hline & Group II & $75.95 \pm 2.49$ & $72.30 \pm 2.08$ & $77.15 \pm 2.43$ & $77.80 \pm 2.13$ \\
\hline & Control & $80.75 \pm 2.38$ & $77.80 \pm 2.35$ & $70.30 \pm 1.74$ & $77.00 \pm 2.01$ \\
\hline \multirow[t]{3}{*}{$\mathrm{TP}\left(\mathrm{msec}^{2} / \mathrm{Hz}\right)$} & Group I & $2449.37 \pm 357.68$ & $2050.14 \pm 309.28$ & $3001.14 \pm 586.05$ & $1912.65 \pm 328.27$ \\
\hline & Group II & $4950.66 \pm 2069.66$ & $4040.75 \pm 1681.27$ & $9895.51 \pm 5385.66^{a}$ & $2223.78 \pm 713.72$ \\
\hline & Control & $3217.81 \pm 606.84$ & $4478.49 \pm 438.04$ & $4961.22 \pm 662.26$ & $3116.45 \pm 671.18$ \\
\hline \multirow[t]{3}{*}{$\mathrm{LF}\left(\mathrm{msec}^{2} / \mathrm{Hz}\right)$} & Group I & $649.47 \pm 121.62$ & $624.84 \pm 153.66^{b}$ & $711.47 \pm 135.92^{\mathrm{a}}$ & $502.95 \pm 80.95$ \\
\hline & Group II & $1361.24 \pm 670.31$ & $1210.635 \pm 594.44$ & $2118.955 \pm 492.60$ & $484.62 \pm 123.20$ \\
\hline & Control & $1102.01 \pm 293.21$ & $1996.14 \pm 329.25$ & $1813.89 \pm 296.82^{\mathrm{a}}$ & $1100.96 \pm 314.10$ \\
\hline \multirow[t]{3}{*}{$\mathrm{HF}\left(\mathrm{msec}^{2} / \mathrm{Hz}\right)$} & Group I & $648.89 \pm 130.67$ & $587.59 \pm 153.26^{b}$ & $994.81 \pm 262.35^{\mathrm{a}, \mathrm{b}}$ & $540.68 \pm 89.01$ \\
\hline & Group II & $1460.595 \pm 606.39$ & $813.35 \pm 127.63$ & $2738.22 \pm 585.43^{b}$ & $705.84 \pm 208.88$ \\
\hline & Control & $885.87 \pm 198.48$ & $1984.14 \pm 297.27$ & $2977.37 \pm 523.46^{\mathrm{a}}$ & $1124.15 \pm 426.01$ \\
\hline \multirow[t]{3}{*}{$\mathrm{LF} / \mathrm{HF}$} & Group I & $1.23 \pm 0.15$ & $1.11 \pm 0.13$ & $1.00 \pm 0.11$ & $1.17 \pm 0.21$ \\
\hline & Group II & $0.94 \pm 0.10$ & $0.94 \pm 0.11$ & $0.74 \pm 0.07$ & $0.76 \pm 0.08$ \\
\hline & Control & $1.34 \pm 0.21$ & $1.05 \pm 0.13$ & $0.71 \pm 0.08$ & $1.17 \pm 0.19$ \\
\hline
\end{tabular}

$\mathrm{n}=60$ /group. Results are presented as the mean \pm standard. HR, heart rate; HRV, heart rate variability; TP, total power; LF, low-frequency power; $\mathrm{HF}$, high-frequency power; $\mathrm{LF} / \mathrm{HF}$, the ratio of $\mathrm{LF}$ to $\mathrm{HF} ; \mathrm{T}_{0}$, prior to the initiation of anesthesia; $\mathrm{T}_{1}$, following the induction of anesthesia; $\mathrm{T}_{2}$, at the commencement of surgery; $\mathrm{T}_{3}$, following the completion of surgery. ${ }^{\mathrm{a}} \mathrm{P}<0.05$, compared with the control; ${ }^{\text {b }} \mathrm{P}<0.05$, compared with group I; ${ }^{\mathrm{c}} \mathrm{P}<0.05$, compared with $\mathrm{T} 0$ within the same group.

following the induction of anesthesia and during surgery than the low-dose spinal anesthesia combined with intravenous anesthesia administered to the control group. Within group I, the administration of $0.5 \mathrm{mg}$ penehyclidine was followed by the stable evolution of HR and HRV parameters, including TP, LF, HF and LF/HF, over the whole study period. The administration of $1.0 \mathrm{mg}$ penehyclidine in group II resulted in higher TP, LF and HF values at the start of surgery compared with the values in group I. In the control group, the HF showed a significant increase at the start of surgery compared with the baseline HF level. At the completion of surgery, the HF had decreased to a level similar to the baseline. Compared with group I, the control group had markedly higher LF and HF values following the induction of anesthesia and during the surgery. All three study groups demonstrated stable LF/HF ratios, with only slight fluctuations observed in groups I and II.

Overall, prior to anesthesia, the activity of parasympathetic and sympathetic nerves, as indicated by the HF, LF and LF/HF, 


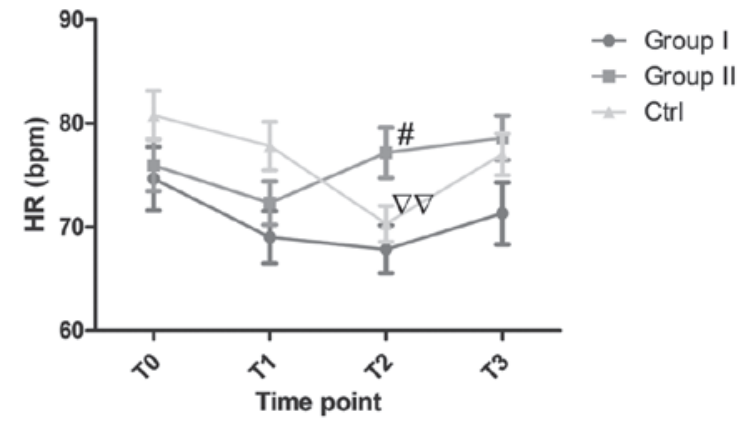

Figure 1. Changes in HR (bpm) in the three study groups. ${ }^{~} \mathrm{P}<0.05$, group II versus group I at $\mathrm{T}_{2} ;{ }^{\nabla} \mathrm{P}<0.01, \mathrm{~T}_{2}$ versus $\mathrm{T}_{0}$ within the control group. Ctrl, control group; HR, heart rate; $\mathrm{T}_{0}$, prior to the initiation of anesthesia; $\mathrm{T}_{1}$, following the induction of anesthesia; $\mathrm{T}_{2}$, at the commencement of surgery; $\mathrm{T}_{3}$, following the completion of surgery.
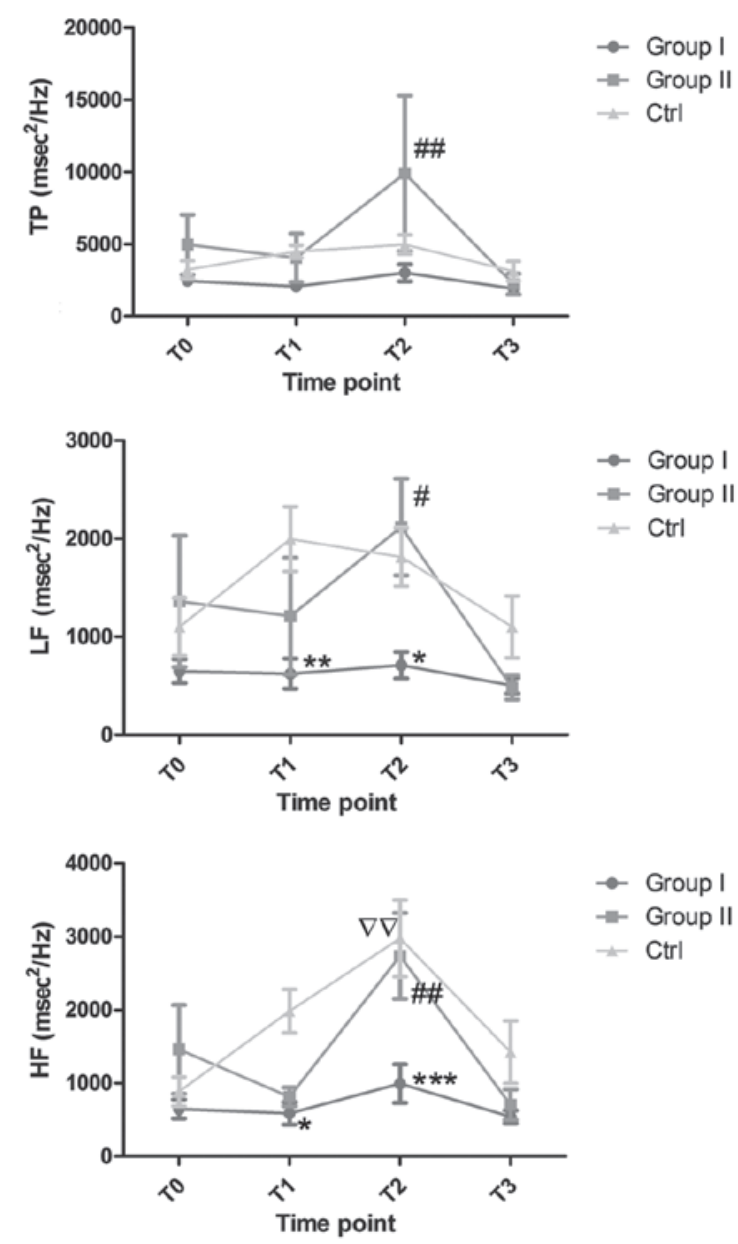

Figure 2. Changes in TP, LF and $\mathrm{HF}\left(\mathrm{msec}^{2} / \mathrm{Hz}\right)$ in the three study groups. ${ }^{*} \mathrm{P}<0.05,{ }^{* *} \mathrm{P}<0.01$ and ${ }^{* * * * *} \mathrm{P}<0.001$, versus the control group; ${ }^{\#} \mathrm{P}<0.05$ and ${ }^{\# \#} \mathrm{P}<0.01$, versus group I (all inter-group comparisons were performed at corresponding time-points). ${ }^{\nabla} \mathrm{P}<0.01, \mathrm{~T}_{2}$ versus $\mathrm{T}_{0}$ within the control group. Ctrl, control group; TP, total power; LF, low-frequency power; HF, high-frequency power; $\mathrm{T}_{0}$, prior to the initiation of anesthesia; $\mathrm{T}_{1}$, following the induction of anesthesia; $T_{2}$, at the commencement of surgery; $T_{3}$, following the completion of surgery.

showed no inter-group differences. All types of anesthetics can modulate hemodynamic status by blocking sympathetic output (15), and different anesthetic approaches can have a variety of effects on HRV and HR (16).

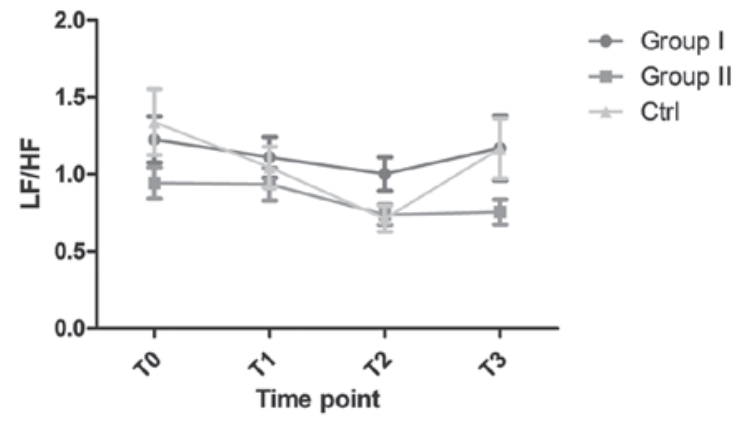

Figure 3. Changes in the LF/HF in the three study groups. No significant differences were observed. Ctrl, control group; LF/HF, the ratio of low-frequency power to high-frequency power; $\mathrm{T}_{0}$, prior to the initiation of anesthesia; $\mathrm{T}_{1}$, following the induction of anesthesia; $\mathrm{T}_{2}$, at the commencement of surgery; $\mathrm{T}_{3}$, following the completion of surgery.

It is well known that pain and psychological stress may be associated with enhanced HR through the activation of the autonomic system (17-19), and feasible pain control and anesthesia may modulate those adaptive responses $(17,20,21)$. Saddle anesthesia, which is performed at the lowest block level of subarachnoid or spinal anesthesia, is widely used in gynecological surgery, including hysteroscopy $(22,23)$. The combination of low-dose saddle anesthesia and intravenous anesthesia, which improves intra-operative management and the post-operative quality of analgesia (13), is widely applied in gynecological surgeries in China (24); however, a common complication associated with spinal anesthesia is sinus bradycardia $(25,26)$. Geffin and Shapiro (25) reported 12 cases of sinus bradycardia and asystole during spinal anesthesia, and the acute event appeared only 15 min after administering the anesthetic injection. Lesser et al (26) also reported >600 cases of bradycardia during neuraxial anesthesia, among which 46 cases were severe ( $\mathrm{HR}<40 \mathrm{bpm})$. A reduction in $\mathrm{HR}$ was also detected in the present study during the surgery. Despite the fact that no incident of bradycardia occurred, the potential risk with this approach should be noted. The occurrence of these complications may be due to an imbalance between the parasympathetic and sympathetic modulation of the HR (13). In the present study, penehyclidine, which is known to have a weak effect on M2 receptors (2), was administered pre-operatively. Upon the administration of 0.5 or $1.0 \mathrm{mg}$ penehyclidine, no clinically significant changes in HR were observed, but $1.0 \mathrm{mg}$ penehyclidine was superior to $0.5 \mathrm{mg}$ penehyclidine in maintaining HR during surgery.

The fluctuation of LF is associated with sympathetic activity, and represents the modulation of HR evoked by the parasympathetic arterial baroreceptor reflex (10). LF is therefore affected by both parasympathetic and sympathetic activities, particularly the modulation of sympathetic activity (27). A significantly lower LF was observed in patients receiving $0.5 \mathrm{mg}$ penehyclidine compared with those under spinal anesthesia both following the induction of anesthesia and during surgery. This decline suggests an attenuated response to sympathetic activation. It has been established that high-intensity pain occurs with sympathetic activation (28); therefore, decreased LF may indicate effective pain control or a notable anti-muscarinic effect of $0.5 \mathrm{mg}$ penehyclidine (29). 
Concomitant with the reduced LF in patients receiving $0.5 \mathrm{mg}$ penehyclidine, a parallel reduction in HF occurred. This result may reflect decreased vagal control of HRV in group I patients compared with patients given low-dose spinal anesthesia combined with intravenous anesthesia. This may be a consequence of the significant decline in respiratory sinus arrhythmia, which is the major component of the HF spectral band (14). In contrast to the low HF of patients receiving penehyclidine, an elevated HF was observed in patients with spinal anesthesia. This elevation of HF was also observed by Hanss et al (30). The results in the study by Hanss et al demonstrated that the main cause of parasympathetic activity excitation was a reflexive shift to parasympathetic activity in response to the inhibition of sympathetic activity (30); however, the results of the present study revealed a parallel elevation of LF and HF. The exact mechanism of this phenomenon was not investigated in this study, but uncontrolled alterations in other factors, such as ambient temperature or noise, physical and psychological stress, or differences in ethnic background, may explain the discrepancies. Generally, anesthetics are assumed to suppress the autonomic system not only by depressing the excitatory sympathetic activity induced by surgery, but also by inhibiting parasympathetic activity $(16,31)$. The results of the present study indicate that $0.5 \mathrm{mg}$ penehyclidine, when combined with spinal and intravenous anesthesia, was more effective at accomplishing this than $1.0 \mathrm{mg}$ penehyclidine.

The combined alterations of LF and HF resulted in an overall stable $\mathrm{LF} / \mathrm{HF}$ ratio during the whole anesthetic period. In the control group, despite the fact that no significant difference was observed during the experimental period, it is possible that the $\mathrm{LF} / \mathrm{HF}$ ratio may have been affected by saddle anesthesia, as the ratio declined gradually between $\mathrm{T}_{0}$ and $\mathrm{T}_{2}$. It has been reported in patients undergoing transurethral surgery that the $\mathrm{LF} / \mathrm{HF}$ ratio decreased significantly following spinal anesthesia with bupivacaine regardless of the addition of fentanyl $(13,32)$. The authors of these studies suggested that this spinal-anesthesia-associated reduction was the result of an imbalance in the sympathovagal system. Similar findings have also been reported in females scheduled for elective Cesarean section under spinal anesthesia with bupivacaine (30). In the present study, an elevated baseline LF/HF ratio dropped during spinal anesthesia, and an attenuation of sympathetic activity was observed. These changes were not evident in the groups injected with either 0.5 or $1.0 \mathrm{mg}$ penehyclidine. These results suggest excellent maintenance of autonomic system balance by penehyclidine.

To the best of our knowledge, this is one of the few investigations of the effect of penehyclidine on HR and HRV indices; however, several limitations should be noted. Firstly, the exact role of HRV analysis remains controversial since it is unclear precisely what HRV measures. HRV may reflect the modulation of the $\mathrm{HR}$ by the sympathetic and parasympathetic systems, but it is not an accurate indicator of the absolute levels of autonomic activity (33). Despite this, HRV is widely accepted as a useful tool to measure the effect of autonomic alterations on HR during anesthesia (34). A second limitation was that the mechanisms of autonomic modulation were not fully accounted for in this study. Other factors, including non-neural mechanisms and psychological effects, could not be assessed by HRV signals (35). Thirdly, this study only measured the perioperative HRV alterations; thus, the long-term effects of penehyclidine cannot be evaluated. Finally, it is not known whether similar observations are likely to apply to patients undergoing other types of surgeries.

In conclusion, the present study demonstrates that $0.5 \mathrm{mg}$ penehyclidine stabilizes potential fluctuations in HRV, without significantly altering the autonomic nerve modulation of HR. Penehyclidine at a dose of $1.0 \mathrm{mg}$ may be superior to $0.5 \mathrm{mg}$ penehyclidine in maintaining a stable $\mathrm{HR}$, and reduces the incidence of bradycardia; however, the higher dose is less effective in maintaining sympathetic and parasympathetic balance.

\section{References}

1. Xiao HT, Liao Z and Tong RS: Penehyclidine hydrochloride: a potential drug for treating COPD by attenuating Toll-like receptors. Drug Des Devel Ther 6: 317-322, 2012.

2. Wang J,Ren Y,Zhu Y, et al: Effect of penehyclidine hydrochloride on the incidence of intra-operative awareness in Chinese patients undergoing breast cancer surgery during general anaesthesia. Anaesthesia 68: 136-141, 2013.

3. Sun YJ, Song DD, Diao YG, Zhou J and Zhang TZ: Penehyclidine hydrochloride preserves the intestinal barrier function in patients undergoing cardiopulmonary bypass. J Thorac Cardiovasc Surg 146: 179-185, 2013.

4. Patterson TA, Lipton JR, Bennett EL and Rosenzweig MR: Cholinergic receptor antagonists impair formation of intermediate-term memory in the chick. Behav Neural Biol 54: 63-74, 1990.

5. Rossman AC: The physiology of the nicotinic acetylcholine receptor and its importance in the administration of anesthesia. AANA J 79: 433-440, 2011.

6. Harvey RD: Muscarinic receptor agonists and antagonists: effects on cardiovascular function. Handb Exp Pharmacol: 299-316, 2012.

7. Xiao HT, Liao Z, Meng XM, Yan XY, Chen SJ and Mo ZJ: Underlying mechanism of penehyclidine hydrochloride on isolated rat uterus. Fundam Clin Pharmacol 23: 419-421, 2009.

8. Zhang Z, Zhuang Y, Ouyang F, Zhang A, Zeng B and Gu M: Penehyclidine enhances the efficacy of tropisetron in prevention of PONV following gynecological laparoscopic surgery. J Anesth 26: 864-869, 2012.

9. No authors listed: Heart rate variability. Standards of measurement, physiological interpretation and clinical use. Task Force of the European Society of Cardiology and the North American Society of Pacing and Electrophysiology. Eur Heart J 17: 354-381, 1996.

10. Akselrod S, Gordon D, Ubel FA, Shannon DC, Berger AC and Cohen RJ: Power spectrum analysis of heart rate fluctuation: a quantitative probe of beat-to-beat cardiovascular control. Science 213: 220-222, 1981.

11. Di Iorio C, Cafiero T and Di Minno RM: The effects of pneumoperitoneum and head-up position on heart rate variability and QT interval dispersion during laparoscopic cholecystectomy. Minerva Anestesiol 76: 882-889, 2010.

12. Sugiura H, Chinushi M, Komura S, Hirono T and Aizawa Y: Heart rate variability is a useful parameter for evaluation of anticholinergic effect associated with inducibility of atrial fibrillation. Pacing Clin Electrophysiol 28: 1208-1214, 2005.

13. Fujiwara Y, Kurokawa S, Shibata Y, Asakura Y, Harado M and Komatsu T: Sympathovagal effects of spinal anaesthesia with intrathecal or intravenous fentanyl assessed by heart rate variability. Acta Anaesthesiol Scand 53: 476-482, 2009.

14. No authors listed: Heart rate variability: standards of measurement, physiological interpretation and clinical use. Task Force of the European Society of Cardiology and the North American Society of Pacing and Electrophysiology. Circulation 93: 1043-1065, 1996.

15. Banz VM, Jakob SM and Inderbitzin D: Review article: improving outcome after major surgery: pathophysiological considerations. Anesth Analg 112: 1147-1155, 2011. 
16. Riznyk L, Fijałkowska M and Przesmycki K: Effects of thiopental and propofol on heart rate variability during fentanyl-based induction of general anesthesia. Pharmacol Rep 57: 128-134, 2005.

17. Lowe NK: The nature of labor pain. Am J Obstet Gynecol 186 (5 Suppl Nature): S16-S24, 2002.

18. Alici G, Ozkan B, Acar G, et al: Evaluation of autonomic functions by heart rate variability after stenting in patients with carotid artery stenosis. Ann Noninvasive Electrocardiol 18: 126-129, 2013.

19. Sato R, Mizuno M, Miura T, et al: Angiotensin receptor blockers regulate the synchronization of circadian rhythms in heart rate and blood pressure. J Hypertens 31: 1233-1238, 2013.

20. Kaneshiro B, Grimes DA and Lopez LM: Pain management for tubal sterilization by hysteroscopy. Cochrane Database Syst Rev 8: CD009251, 2012.

21. Griffis CA, Crabb Breen E, Compton P, et al: Acute painful stress and inflammatory mediator production. Neuroimmunomodulation 20: 127-133, 2013.

22. Florio P, Puzzutiello R, Filippeschi M, et al: Low-dose spinal anesthesia with hyperbaric bupivacaine with intrathecal fentanyl for operative hysteroscopy: a case series study. J Minim Invasive Gynecol 19: 107-112, 2012

23. Cesur M, Alici HA, Erdem AF, Borekci B and Silbir F: Spinal anesthesia with sequential administration of plain and hyperbaric bupivacaine provides satisfactory analgesia with hemodynamic stability in cesarean section. Int J Obstet Anesth 17: 217-222, 2008.

24. Guo SB, Lin M and Hao ZB: The application of combination of spinal anesthesia and intraveous anesthesia in gynecological laproscopy. Zhong Guo Xian Dai Yao Wu Ying Yong 3: 90, 2009 (In Chinese).

25. Geffin B and Shapiro L: Sinus bradycardia and asystole during spinal and epidural anesthesia: a report of 13 cases. J Clin Anesth 10: 278-285, 1998.
26. Lesser JB, Sanborn KV, Valskys R and Kuroda M: Severe bradycardia during spinal and epidural anesthesia recorded by an anesthesia information management system. Anesthesiology 99: 859-866, 2003.

27. Malliani A, Pagani M, Lombardi F and Cerutti S: Cardiovascular neural regulation explored in the frequency domain. Circulation 84: 482-492, 1991.

28. Carr DB and Goudas LC: Acute pain. Lancet 353: 2051-2058, 1999.

29. Weissman A, Torkhov O, Weissman AI and Drugan A: The effects of meperidine and epidural analgesia in labor on maternal heart rate variability. Int J Obstet Anesth 18: 118-124, 2009.

30. Hanss R, Ohnesorge H, Kaufmann M, et al: Changes in heart rate variability may reflect sympatholysis during spinal anaesthesia. Acta Anaesthesiol Scand 51: 1297-1304, 2007.

31. Nakatsuka I, Ochiai R and Takeda J: Changes in heart rate variability in sevoflurane and nitrous oxide anesthesia: effects of respiration and depth of anesthesia. J Clin Anesth 14: 196-200, 2002.

32. Fujiwara Y, Sato Y, Shibata Y, Asakura Y, Nishiwaki K and Komatsu T: A greater decrease in blood pressure after spinal anaesthesia in patients with low entropy of the RR interval. Acta Anaesthesiol Scand 51: 1161-1165, 2007.

33. Haney MF and Wiklund U: Can heart rate variability become a screening tool for anesthesia-related hypotension? Acta Anaesthesiol Scand 51: 1289-1291, 2007.

34. Vettorello M, Colombo R, De Grandis CE, Costantini E and Raimondi F: Effect of fentanyl on heart rate variability during spontaneous and paced breathing in healthy volunteers. Acta Anaesthesiol Scand 52: 1064-1070, 2008.

35. Parati G, Mancia G, Di Rienzo M and Castiglioni P: Point: cardiovascular variability is/is not an index of autonomic control of circulation. J Appl Physiol (1985) 101: 676-678, discussion 681-682, 2006. 